\title{
IS MARTIAL ARTS STUDIES TRIVIAL?
}

\section{PAUL BOWMAN AND BENJAMIN N. JUDKINS}

DOI

10.18573/j.2017.10183

\section{ABSTRACT}

Before introducing the articles comprising this issue of Martial Arts Studies, this editorial first undertakes a sustained reflection on the question of whether the emergent field of martial arts studies might be regarded as trivial. In doing so, it explores possible rationales and raisons d'être of the field in terms of a reflection on the legitimation of academic subjects, especially those closest to martial arts studies, from which martial arts studies can be said to have emerged. The first draft of this reflection was originally written by Bowman in response to certain reactions to his academic interest in martial arts (hence the occasional use of the pronoun 'I', rather than 'we'), but Judkins proposed that the piece form part of this issue's editorial, because of the importance of thinking about what this 'martial arts studies' thing is that we are doing, what the point of it may be, and whether or not it may be trivial.

\section{KEYWORDS}

martial arts, triviality, martial arts studies, disciplinarity, legitimation
Eyebrows raise. Sometimes there are sniggers. Glances are exchanged. Some people look confused. Some say 'what?' People seem surprised. 'Martial arts?', they ask, incredulously. 'Why?' Or even, 'Martial arts studies? What is that?' These kinds of reactions come from all sorts of people - whether academics or not. No one ever just nods and says, 'Oh, ok', the way they would if you'd just said Romantic poetry or urban planning or philosophy or music or fluid dynamics, or the way they might even if you'd just said that you 'do' one of the many obscure and often peculiarly named branches of modern science (whether neuroparasitology, nutrigenomics, cliodynamics, or something even more unexpected).

Sometimes there is surprise and delight. Sometimes there are other sentiments (to be confirmed). A lot of it - whether shock, delight, dismay, concern, or confusion - should be unsurprising, really. On the one hand, people are used to hearing about the familiar subjects of the arts, humanities, and social sciences - the old, traditional fields. On the other hand, when it comes to the sciences, people almost expect to hear of new and unintelligible fields with exotic Latinate names, involving odd prefixes combined with all kinds of 'ologies', 'ographies', 'omatics', 'otics', 'amics', and 'omics'. We measure our social progress through this ever-rising spiral of technical specialization.

But martial arts as a field of academic study? Martial arts studies? This kind of thing sounds highly dubious to most ears. It doesn't seem to need explanation as much as it needs justification. What reason could there be for the existence of something so ... so what? Words come out of the woodwork: iffy, dodgy, nerdy, niche, weird, boyish, hobbyist, or - of course - trivial.

What triviality is martial arts studies? What indulgence? What narcissism, navel gazing, nothingness, even naughtiness is this?

Our questions may seem hyperbolical. But we recall a rhetorical question posed by Stuart Hall about cultural studies in the very early 1990s, in an essay written at the height of the era of the full horror of the AIDS epidemic. Hall asks: 'Against the urgency of people dying in 
MARTIAL ARTS STUDIES the streets, what in God's name is the point of cultural studies?' [Hall 1992: 285]. Hall posed this question to illustrate the marginality and ineffectuality of academics who saw themselves as working in a field that sought to make a real difference to the world, a real difference in the world - because, as another famous thinker famously put it, surely the point is not merely to interpret or understand the world, 'the point is to change it'.

Is martial arts studies 'mere' interpretation? Is it only empirical observation? Or might it be something more?

There are other interpretations of our academic obligations than this, of course [Wetzler 2015]. One does not have to struggle to change the world to work in academia. Indeed, one caricature of the academic figure is he or she who retreats from the world, who hides in books, who is indeed incompetent in the 'real world'. Nonetheless, whether our understanding of our academic activities boils down either to trying to interpret the world or to trying to change the world, what in God's name is the point of martial arts studies?

Shortly after publishing my first book on Bruce Lee in 2010 [Bowman 2010], I was discussing my future research plans with a senior colleague. I stated my interest in developing further some of the lines of enquiry opened up by my work on Bruce Lee. (No one was talking about 'martial arts studies' then. It wasn't yet a 'thing' [Farrer and WhalenBridge 2011].) In response, my colleague said, with a kind of paternal or avuncular concern (that suggested he thought I might be making a big mistake), 'Yeah, but that's just a bit...' and with a wince and a shrug and an expression that said, 'You know what I mean, don't you? Don't make me say it', his sentence tailed off, inviting me, obliging me, to finish it in my head myself. One word leapt up for the job: Trivial. 'That sort of thing is just a bit [trivial]'.

Of course, we know where he was coming from. Two places. A nexus, or chiasmus. Two forces converged, driving his opinion. Two fields of legitimation. The first work is the general force that has been exerting itself on the arts, humanities, and social sciences since at least the 1960s. This might be called the force of the political. Specifically, it is the force of the increasing consensus that grew to a crescendo by the final decades of the twentieth century, which held that the way to study something, the way to justify giving attention to something, the way to redeem something and to elevate it to legitimacy in the university, was to show that it was political [Young 1992; Readings 1996].

The second force in play in my colleague's words was the age-old sense that, to borrow a phrase, 'that just ain't how we do things around here'. In many departments, the obligation to work within the paradigm of the political has been interpreted and assumed in a very particular (literal and direct) way, and Bruce Lee and martial arts don't obviously, or self-evidently, fit within that space.

This is not to say that Bruce Lee or martial arts were necessarily anathema to that space. But such objects of attention were always likely to be filed as 'niche'. In a heavily journalism-focused school of 'Journalism, Media and Cultural Studies', Bruce Lee and martial arts could be made to 'fit in' - as part of the general non-journalism background of media studies and cultural studies. But not as a 
MARTIAL ARTS STUDIES

particularly central part even of them. Bruce Lee or other things related to martial arts would always fall into the subcategories of 'film', on the one hand, and 'popular culture' (or, worse, fan/subculture), on the other. Indeed, such foci would arguably fall further, into such unspoken or unspeakable sub-subcategories as non-serious film, and playful - or trivial - popular culture. ${ }^{1}$ Even the historical study of these subjects tends to focus on questions of the 'social' and 'local', rather than the more prestigious (and properly political) categories of military, diplomatic, or national history.

The problem is that the kinds of things that the subject of martial arts seems to open out onto are exactly the kinds of things that a few decades ago caused problems for the image and reputation of the fledgling fields of media studies and cultural studies. They are the kinds of things that once caused people to regard media studies and cultural studies as 'Mickey Mouse subjects' - i.e., non-serious, non-central, nonimportant: trivial [Young 1999]. Likewise, the sociology of sport and other recreational pursuits never seem to carry the same prestige as core topics like economic class or religion.

The salvation or salvaging of the reputations of media studies and cultural studies came in the form of the quiet victory within the university of the idea that more or less everything is contingent and hence more or less political [Mowitt 2003]. Politics - or, more precisely, 'the political' - became the sign under which certain previously excluded, overlooked, ignored, or disparaged things could justifiably and hence legitimately be studied [Marchart 2007]. Women's things, ethnic minorities' things, postcolonial things, working class things, local things, new things, controversial things, and so on.

Unfortunately, it takes about three stages of argument to persuade the uninitiated that things to do with martial arts, like, say, Bruce Lee, are in some sense political and hence in some sense important and hence worthy of at least some kind of academic time and attention [Bowman 2010; Judkins and Nielson 2015]. This means that, even if everything is equal in the eyes of the paradigm of the political (because everything is in some sense political), it is still a hell of a lot easier to show that some parts of media, culture, and society are 'self-evidently' political and hence important. These include such 'obviously political' parts of media, culture, and society as, say, serious news journalism, serious policy debates, protest, and so on.

So, things like journalism, news media, and protest, along with matters of gender and race and disability in representation, and so on, are easy to perceive as proper objects or fields to be privileged. This is because they are easy to regard as being somehow closer to politics or the political - or 'more political' - than certain other kinds of media and other kinds of cultural practice - like, for example, martial arts.

The fact that all things are potentially equal within the paradigm of the political does not mitigate the fact that it will always take about three argumentative steps to prove or persuade someone that martial

$1 \quad$ People who are into things from popular culture - and even people who study such things - are regularly regarded as 'fans'; but people who are heavily into, say, broadsheet journalism or politics or news media are never called 'fans'. You never have a 'fan' of The Times or of the labour movement. 
MARTIAL ARTS STUDIES arts are political (and 'therefore' valuable) in any number of possible ways. On the other hand, it takes between none and one step to show that political foci and political projects are political. They already seem political because they already seem political - even if it is actually possible to argue that they are not [Žižek 2001; Bowman 2008].

Accordingly, senses and then forces of propriety (and impropriety) visà-vis academic foci take hold.

Our anecdotes involve senior colleagues conveying a judgement that may be regarded as intentionally or unintentionally subtly seeking to discourage a junior colleague from pursuing a certain style or orientation of work. Norms and values are being implied here: good things to do and less good things to do.

Of course, this anecdote is just an anecdote. But we could follow it up with quite a few others. In fact, our opening words were a distillation of many possible anecdotes. But, what is the status of such anecdotes? And what of the innumerable possible counter-balancing anecdotes that could be considered?

In a rightly renowned essay called 'Banality in Cultural Studies', Meaghan Morris says that anecdotes 'are not expressions of personal experience, but allegorical expositions of a model of the way the world can be said to be working. So anecdotes need not be true stories, but they must be functional in a given exchange' [Morris 1988: 7].

Our anecdotes seek to say something about the way at least some parts of the world can be said to be working, at least in relation to the academic study of martial arts. Of course, the world of human interactions and conversational exchanges can be seen as an almost infinite ocean of potential anecdotes, so are we merely singling out only the reactions that suit our purpose? Indeed, are we maybe being a bit too sensitive to any perceived criticism of our shared field of work, whether real or imagined, no matter how slight the sleight may be, when evaluated according to more objective yardsticks? Do we protest too much?

Maybe so, but even if we are being hyperbolic, or making a mountain out of a molehill, we believe that there will nonetheless be some value in the exercise of reflecting on the problem posed. Indeed, it is arguably the case that any and all serious, rigorous, and sustained academic treatment of anything must necessarily magnify and intensify the object of attention's status - and, in other words, make a mountain out of it, even when we know it is not a mountain, even if it really is a molehill. To someone seriously studying molehills, a molehill is a mountain, at least, if not bigger and more significant. In fact, to someone studying molehills, a mountain may be entirely insignificant.

To put all of this in slightly different terms: is there an issue here that is larger, more far reaching or significant than these anecdotes themselves and their local interpretation? How do they connect with ways that the world might be working, and what might be the significance, importance, or consequences of that?

Elsewhere in 'Banality in Cultural Studies', Morris discusses the dynamics of the then relatively new (and still very Japanese) term 'boom' - as in, 'economic boom'. As Morris notes via a variety of 
MARTIAL ARTS STUDIES examples, in a period of boom, a certain kind of explosion in activity often goes hand in hand with another kind of limitation or prohibition. In her words, a boom involves not only 'passion and activity' but also 'a pre-emptive prohibition and limitation of activity' [1988: 5]. As such, in a boom, there are ample opportunities for the exploration and expansion of activities that are popular (or booming). But, by the same token, any attempts to engage in non-boom activities are likely to be met with blank stares, closed doors, and dead ends.

In thinking about the features of a boom, Morris argues that there is a significant 'difference between the Japanese concept of cultural boom, and the older European notion of "fashion"' [1988: 4]. Relating it to academia, she observes:

The notion of 'intellectual fashion' ... is usually used to denigrate passion and enthusiasm as 'fickle' - in order to imply that real, solid scholarship is going on somewhere in spite of the market, within which it will nonetheless find its true place of recognition once the fuss of fashion subsides. A boom, however, overtly defines and directs what can be done at a given moment. [Indeed] booms positively shape the possible, by stabilising a temporary horizon in relation to which one cannot claim a position of definite exteriority, [meaning that] it also becomes possible to think more carefully the politics of one's own participation and complicity.

[Morris 1988: 5]

So, if and where there is a boom, there is possibility, facility, propensity, energy, ability. If and where there is not, there is resistance, apathy, confusion, skepticism, and so on. Indeed, as well as the lack of interest that may face any non-boom activity, there may actually be a lack of ability to imagine why anyone could be interested in it.

What, then, is the situation vis-à-vis martial arts studies? Is martial arts studies facing a boom, or facing its opposite - which is not a 'bust', as it hasn't yet had its day in the sun; so some kind of 'pre-emptive prohibition and limitation of activity'? What would be the larger, only dimly perceived, intellectual trends which define this gravitational horizon?

Our sense is that martial arts studies is currently emerging thanks to the ground opened up by the victories won by subjects like cultural studies, part of whose success was the demonstration of the political dimensions of culture and the contingency of norms, hegemonic values, and institutional investments. While not compiling a comprehensive list here and now, we might say that the movements of which cultural studies was a part revealed the extent to which our educations and our institutions were white, Western, male, heterosexual, Eurocentric, and upper class [Storey 2000]. All of these things were deemed to require redress on ethical and political grounds. And a windfall gain of the general deconstruction of elitist tastes, values, formations, and practices in so many of their incarnations was the attendant ability to revalue hitherto devalued things - not only non-white and non-male things, but also things that had been regarded as supposedly lowbrow, popular, low-class, and - hence - trivial. Things like martial arts in their many incarnations, as well as the media, history, and training methods that accompany them. 
MARTIAL ARTS STUDIES
So, in one sense, the emergence of martial arts studies owes a lot to the intentional or unintentional redemption or salvaging and revaluation of the supposedly secondary, inferior, inauthentic, non-serious, and trivial that took place in and around cultural studies. But on the flipside, perhaps this is also a source of problems for martial arts studies. For, thanks to it, martial arts studies becomes an heir to the most problematic inheritance of the deconstruction and reconstruction of academia - namely, the trivial. This is why we suggest that martial arts studies should expect to attract as much perplexity and even vitriol and vituperation as subjects like media studies, audience studies, fan studies, game studies, fashion studies, and so on - all of which have for a long time easily drawn flak for sounding like so many different names for something that should really just be called Triviality Studies.

As many people intuitively know, these kinds of problems might always be circumvented or deferred by sheltering or smuggling martial arts studies under more established umbrellas, as in such formulations as: I'm an anthropologist, and I research...; I'm a historian, and I research...; I'm an ethnographer, and I research...; I'm a sociologist, and I research...; and so on. In this way, the ground is prepared for the introduction of martial arts as a more obviously legitimate object of studies by framing it as merely one of the many possible objects of an already valid and valued field. Or, alternatively, the martial arts might be transformed from a dependent variable (the thing examined) to an independent variable (an explanatory factor) within a better-established research program.

Such an approach has its virtues. Indeed, how many of us could actually say that we work in schools or departments of martial arts studies, or that we principally teach modules, courses, or degrees in martial arts studies? And for those handful of people in the world who could say something like this, what exactly is it that they are working in or teaching?

Both of these questions point to a problematic that I tried to think through in my 2015 book, Martial Arts Studies: Disrupting Disciplinary Boundaries [Bowman 2015]. This problematic boils down to the question of whether martial arts studies could be said to exist as an academic field, and what it means to say that it does, or to operate as if it does. Phrased differently: we already know that martial arts studies can emerge parasitically, and exist as a kind of supplement, sub-field, or focus within other umbrella disciplines and departments. That has never really been in doubt. Many scholars have touched on the martial arts over the decades. Yet, might martial arts studies exist somehow independently? Is it possible to invent martial arts studies as an independent or discrete entity, and what would it look like if we were to try?

It soon becomes apparent that posing such questions very quickly opens out onto a whole range of questions about academic subjects, a questioning that could - perhaps should - ultimately open out into a far reaching reflection on what a university subject (or discipline or field) is, what university disciplinary and managerial divisions and subdivisions are, why they exist, what they do, whether we 'need' them, what sort of interests and outcomes they serve, and whether we might dispense with them, or at least move them into different relations and dynamics. 
MARTIAL ARTS STUDIES
I spent quite a long time on this (which I think is a fascinating and important) subject in that 2015 book, so we will not tarry too long in the same terrain again here. Instead, we will try to move things along by maintaining a focus on the question of triviality, and specifically the triviality of martial arts studies, before coming back to these questions about the possible forms of existence of martial arts studies.

The Oxford English Dictionary says a lot of things about the words trivia, trivial, and the word trivium, from which they all substantially derive. For, as the $O E D$ tells us, trivial once referred to belonging to the trivium of medieval university studies, or 'the lower division of the seven liberal arts, comprising grammar, rhetoric, and logic'. We could make a lot of this, but to do so would involve sophistry. This is because when people say trivial today they do not intend to mean anything related to this, unless they are having a specialist discussion on the subject of the medieval university. Nor do people mean triple or threefold. Nor do they mean 'placed where three roads meet'. But they may mean 'Such as may be met with anywhere; common, commonplace, ordinary, everyday, familiar, trite', or - more likely - 'Of small account, little esteemed, paltry, poor; trifling, inconsiderable, unimportant, slight'.

There are other technical meanings for trivial that are used in fields like zoology and a range of sciences, but none of these relate to what is most commonly meant by trivial. However, one meaning of trivial that comes from mathematics is suggestive to the point of being poetic. In it, trivial means: 'Of no consequence or interest, e.g. because equal to zero'. So, we might say, trivial most often evokes something that is so ordinary, commonplace, familiar, or inconsequential that it is effectively deemed equal to zero. Or, if not nothing, then at least very little, almost nothing.

Again, we could make much of this and use all of the kinds of arguments made in cultural studies and gender studies and postcolonial studies and so on to argue for the revaluation, redemption, or reclamation of martial arts. But we will not do this here, because we should all already know how to do this. I'm sure I am not the only one who has, on many occasions - as I did in response to my anecdotal colleague - persuaded others of the value of martial arts studies by playing the political card. In Theorizing Bruce Lee, I actually ran through a check list of many of the key organising themes and problematics that organise not only cultural studies but also many other fields - such as ethnicity, postcoloniality, polyvocality, polysemy, multimediality, cultural translation, intertextuality, sex/gender identity performativity, postmodernity, enculturation, hegemony, commodification, resistance and subversion, and so on - and showed the extent to which Bruce Lee ticked all of such fields' boxes. In their study The Creation of Wing Chun, Judkins and Nielson engaged in a similar exercise tackling themes such as imperialism, resistance, modernization, marginality, nationalism, and social violence.

There are other ways to argue for the legitimacy of studies of martial arts, of course: legitimation by numbers (just look at how many people in the world do martial arts), legitimation by money (just look at how big a range of businesses martial arts are), legitimation by area (just look at how central martial arts are to nationalism and national identity building projects, particularly across Asia), legitimation by UNESCO (if it's good enough for UNESCO to call it 'intangible cultural heritage', 
MARTIAL

ARTS STUDIES it's good enough for a study, right?), legitimation by demographics, pedagogics, identity politics, ideological orientation, discursive status, and so on and so forth.

But we know all of this. If Judkins' wide-ranging and field-defining blog Kung Fu Tea has taught us one single thing, it is this: that, nationally and internationally, martial arts are massive.

But lots of things are massive. Narcissism, nose-picking, and trainspotting, for instance, might all be said to be massive. The question is whether such things might warrant an academic field and/or whether such a field might be deemed trivial.

To move things forward, perhaps what is needed here is to note that one vital thing the $O E D$ does not tell us about the notion of the trivial is that it is radically relational and that reflection on what a given perspective, person, or situation deems to be trivial constitutes something of a royal road to the unconscious biases or unthought regions of that perspective, person, or situation itself.

So, if we are in a conversation with our critic, we can deconstruct any criticism of our position that proceeds according to the argument about something's triviality. Or, better, we can engage in discussion and win the argument and persuade our interlocutor of the validity or nontriviality of martial arts and martial arts studies. And so on. In fact, as I have just suggested, there are a range of options.

But whatever we decide to do, it strikes us as both theoretically and practically useful always to proceed in full awareness of the fact that all of us are very often going to regard certain other things as trivial. Moreover, some people, hostile to this or that academic focus or approach, are often likely to be inclined to wield whatever they think is properly important like a kind of sledgehammer to try to smash whatever it is they think is trivial. At cultural studies conferences it is a common (perhaps therefore apparently trivial - certainly frequent) occurrence for any session of presentations on more or less any subject - anything at all - you name it - to provoke a member of the audience to cry out, in exasperation, something along the lines of, 'Why are you all wasting your time with this? What about the war?!'

Wars are serious. When measured against the seriousness of an ongoing war, and people dying in the streets, academic studies of more or less anything, in any discipline, will almost always seem somewhat trivial.

Of course, the irony is that some people working in martial arts studies may well have compelling, informed, intelligent, specialist, rare, or valuable insights into questions of war and violence. But a further and more pertinent irony is that experts and specialists on modern war or social violence are actually likely to be in the minority in martial arts studies. This is so even though 'martial' has to do with war. Nonetheless, the peculiarity is that - for a whole host of linguistic, cultural, and historical reasons - many of us mostly seem to forget the most literal meaning of the word 'martial' as soon as it is combined with the word 'art'. Something happens that is not entirely unlike the way the most obvious meaning of the word 'pretty' is evacuated and utterly transformed when it is connected with the word 'ugly'. 
MARTIAL ARTS STUDIES
This is why the very term 'martial arts studies' is rarely-to-never decoded, translated, defined, or interpreted as meaning anything like 'studies of the art of war' - even and perhaps especially within martial arts studies itself. Indeed, the tendency of the field today exhibits a definite bias towards studying armed and unarmed embodied fighting, which is the very thing that Peter Lorge has suggested Chinese military experts throughout history have long regarded as being 'a developmental rather than a functional skill in the army' [Lorge 2012: Loc 3506]. The myriad other realms and components of the arts of war (or rebellion or riot) are rarely centralised or foregrounded in martial arts studies. Indeed, if the term 'martial arts studies' really meant 'studies of the arts of war' to us, this would make the field into a very different kind of thing - something that arguably already exists, under a range of different names: war studies, conflict studies, peace studies, security studies, and so on and so forth. But do war studies, conflict studies, or peace studies really capture or cover what we tend to think martial arts studies is or should be? And if so, why the new name, the new demarcation, if martial arts studies is just another version of something or some things that already exist? What the hell is martial arts studies supposed to be anyway?

I have argued elsewhere against the drive to define martial arts and hence thereby to demarcate martial arts studies [Bowman 2017b]. As I have suggested on several occasions, such an orientation is naïve in a number of ways. And we will add here and now, in this context, that succumbing to such an orientation (the drive to define, or the 'definition drive', if you will) would achieve the opposite of what most pro-definition academics hope for: rather than conferring scientific seriousness onto the field, it would most likely tend to work to guarantee the marginality and triviality of any martial arts studies generated or facilitated by imposing a strict definition of martial arts. Or, to put it slightly differently, such a move would tend to isolate martial arts studies from the critical questions of the day, rather than asking what our hard won understanding might contribute.

This has been addressed before [Bowman 2017a, 2017b]. To avoid being repetitive, let us say something slightly different this time. This time, we will borrow an argument made by Mark Singleton about the word 'yoga' [Singleton 2010]. Specifically, in a fascinating study of yoga, Singleton notes that, over the centuries, and in different contexts and different minds, the word 'yoga' has long existed; but it has always referred to ever-changing and very different things - ideas, practices, ideologies, orthodoxies, orthopraxies, and so on. In the face of such polysemy, rather than adopting a position that would force him into feeling the need to specify anything like 'this is real yoga but that is not real yoga', Singleton instead proposes that we always treat the word yoga as a homonym.

Homonyms are words that are both spelled the same and pronounced the same but mean different things. When I say 'martial arts' and you say 'martial arts', we may well be thinking of very different things, with different forms, contents, places, roles, functions, associations, implications, and so on. But we will undoubtedly be able to talk about this difference because an interesting thing about these homonyms is that the meanings tend to cluster together, overlap each other, interact together, reflect (and reflect on) each other, and so on. 
MARTIAL ARTS STUDIES
This is why not only 'we specialists' but also all practitioners and, most importantly perhaps, myriad non-practitioners and people who simply know as close to nothing as is imaginable about 'martial arts' will all have an immediate pre-critical inkling of what the 'martial arts' of 'martial arts studies' is most likely referring to. This is because the term 'martial arts' is a discursive achievement - a construct, not a trans-historical datum. It is a type of popular conversation (rather than a singular thing) that is already familiar to all.

Despite having a long history, 'martial arts' is nonetheless a comparatively recent term within English language popular usage. That is to say, it is a current term. Yes, it also has a long history. But to claim that the English language term 'martial arts', in the ways we use it today, is much older than the late 1960s is much the same as claiming that when people say 'trivial' they are referring to the disciplinary demarcations of the mediaeval university or that they are referring to 'where three roads meet'. That is to say, it is a claim that overlooks the words' currency, or current-ness. Martial arts has a certain currency now, in Anglophone cultures and societies. Again, it points to trends and conversations much more than things.

Perhaps this widespread current currency is why studies of martial arts have so definitively broken free from anthropological or area studies paradigms, in which many research programmes are organised by notions of the rituals of groups. As popular as such approaches continue to be, postcolonialist deconstruction has taught us that, while subjects such as anthropology and area studies continue to invent their objects in terms of ideas about rituals and groups, white Western thinkers tend not to be quite as keen on the idea that white Western cultures and societies are themselves organised by groups and rituals. That kind of thing is easier to see in and as the societies of the others, not us and ours [Fabian 1983; Spivak 1993]. So, if it's something 'we're into', something that's happening here, it surely can't be the traditional indigenous ritual practice of natives, now can it?

Nowadays, the flipside of this situation is never too far away. This is the belated realisation that the apparently ancient traditional ritual practices of the natives over there always turn out to be complex discursive formations and constructions, or, as we now so easily say, a heady mix of 'orientalisms' and 'invented traditions'. There is a lot to say about this kind of thing. But, in terms of thinking about 'currencies' and 'booms', one thing that leaps out at us as truly remarkable, and surely significant, is the enduring currency of terms like 'orientalism' and 'invented tradition' in the generation and organisation of so much research. How great are we at finding 'our' orientalism and 'their' invented traditions? Surely, we should be great at it: we've been doing this kind of thing over and over again since the 1970s!

Discussion of all of this could take us far afield. But the point we wish to make here is that, as much as so many of us are so ready, willing, and able to carry out discursive or conjunctural analyses of our objects of study these days (as long as our objects of study are others: the practices of natives, the practices of tribes, or subcultures, or working classes, or bourgeoisies, and so on), surely we have an attending obligation to consider the question of how and why we ourselves are doing what we do in the ways that we do it. 
MARTIAL ARTS STUDIES
The question is one of what the discursive conditions of possibility for today's emergence of an academic thing called martial arts studies are or have been. We have suggested that part of our enabling conditions relate to the revaluation of erstwhile trivia by former trailblazing projects like cultural studies. Might another key component relate to the enormous productivity of notions like orientalism and invented tradition? These terms have been available since the late seventies and early eighties, yet they show no signs of fatigue, which suggests that their work is not yet done (unlike countless other once fashionable or once booming theoretical terms that seem to have evaporated today but are presumably still skulking in the shadows or waiting in the wings - like the Baudrillardian ideas of 'banal strategies' and 'fatal strategies' that Morris's essay notes were dominating cultural studies in the 1980s. Are we still thinking about banal strategies and fatal strategies? Is that problematic even remembered today?).

But, wait. Do reflections like this, on our enabling and organising terms, take the entire field of martial arts studies too far afield? Is such a kind of self-reflection narcissistic or trivial? It is easy to disagree with such an idea. There is immense value and opportunity for mastering and improving our practices if we learn more about the forces that mould and shape our activities. (We may not want to apply the notion of 'invented tradition' to our own activities, for instance; but we ought to think about why that is and why we are happy to apply it elsewhere.)

In fact, as much as I am often fascinated by the kinds of objects of attention that are emerging in martial arts studies, I am possibly even more animated by the challenge of thinking about where we are now. This is not simply to do with the 'newness' of the field, but rather with what can be seen to be happening right now in terms of discursive creation, writing, construction, invention, and the articulation and stabilisation of martial arts studies as a 'thing'.

We are still close enough to 'the start' that the publication of a new book generates widespread excitement and gets everyone talking, and for the announcement of a conference in the near future to get everyone looking at their diaries and hoping that they might be able to afford to go. New scholarly English language books on martial arts are not yet merely felt as a drop in the ocean. Their status as 'a contribution' is still easily palpable.

Obviously, as this process continues and grows, the status of each new conference, paper, article, chapter, journal issue, book collection, and monograph will undoubtedly change, and maybe ultimately seem to diminish. The field will be elaborated and proliferate and in time it will surely mutate and reposition. But our hope (and our sense) is that this will not be until after something has happened.

Something is happening. Something has already started to happen. We have, at the very least, already resoundingly answered at least one question that haunted so many of us for so long: Will martial arts ever be a valid object of academic study? Remember how often and how pessimistically this question was posed? But now the answer is: Yes, look, it can be, it is, and look how diversely and dynamically connected with so many other things martial arts always turn out to be! 
MARTIAL ARTS STUDIES
So, to use a well-worn question form: If martial arts studies is a thing, what kind of a thing is it? What is this a case of? And, again: If something is happening, what kind of a something is it - and what kind of a happening?

To take any or all of these questions, in isolation or at the same time, any answer would always involve asserting that martial arts studies is emerging to answer a demand - not just an academic demand, whether by 'academic demand' we mean in the sense of 'knowledge for knowledge's sake' (i.e., a demand to fill a perceived hole in the field of knowledge, simply because we have perceived that a hole is there) or in the pejorative sense of being a 'merely academic' matter. Rather, martial arts studies is emerging because an untold number of conditions have been met that now allow into the university the kind of ongoing and widespread intellectualisation of martial arts that has been taking place for many years outside of the university [Bowman 2015, 2017a, 2017b].

It is critical not to forget that intellectual discourse and scholarship on martial arts has long taken place, but mainly outside of standard university channels, and outside of the West. So, in this sense, Anglophone martial arts studies is belated. But nonetheless, finally, today - and helped in large part by having organised itself around and in terms of the questions, concerns, languages, vocabularies, and purviews of established fields like cultural studies, anthropology, history, and sociology - academic scholars have begun to find a way to legitimise martial arts as an academic field.

This kind of legitimisation is principally at the research level. Wherever martial arts studies has so far been instituted at the pedagogical level - that is, as a unique or discrete degree level subject taught to undergraduates - this has principally taken the form of practical and vocational orientations, i.e., as degrees involving learning martial arts and learning about them in terms physical education delivery and selfdefence pedagogy or industry [but see also Wile 2014].

So, there is a difference between the research field and the pedagogical field. Of course, that's not to say there are not connections and crossovers. But the point is that there have so far been different orientations and modes of legitimation in which the research field has been legitimating itself via questions and concerns of critical, social scientific, and historical theory, while pedagogical instantiations of the field have proceeded according to a range of vocational, physical education, and industry questions and concerns.

The relations between these two levels are always going to be complex, and often fraught. But the homonym 'martial arts' that organises all levels and orientations can and will facilitate many leaps and links and crossovers and connections, and could indeed coalesce at times and in places into enormously exciting and genuinely multiple and heterogeneous experimental interdisciplinarities.

From any academic perspective, there is very little to no triviality in this. Similarly, if money talks, there is no triviality in securing research grants, establishing research centres, setting up modules and courses and degrees. There is no triviality in cross-disciplinary discourses that have the capacity not merely to enrich but to alter the disciplines from which they began. Nor is there triviality in transforming the wider cultural discourses on martial arts - in, say, demonstrating orientalism, 
MARTIAL ARTS STUDIES

or debunking myths, or revealing the inventedness of traditions. Orientalism and myths and invented traditions are big business. The stakes are high. So, this kind of work has the capacity - perhaps the obligation - to change things.

By the same token, there is therefore a strong corresponding undercurrent of force or even a kind of 'violence' here (whether acknowledged or unacknowledged). This arises because, with the emergence of academic martial arts studies, what happens is the pitting of one kind of orientation against another, one kind of livelihood against another, one kind of tradition against another, one kind of myth against another. This takes place both at and across internal university borders, as well as at the borders and across the realms straddling the inside of the university and the outside [Bowman 2015, 2017a]. It is wise to remember that one never explores an 'invented tradition' in a vacuum. Such a conversation is bound to have an effect on individuals and institutions that have looked to such stories as a source of legitimacy and an assurance of authenticity in a shifting world.

These are just some of the levels, some of the contexts, some of the scenes and sites of struggle and activity of the emergence of martial arts studies. All in all, when thinking about martial arts studies, we should perhaps take the famous phrase of Pierre Bourdieu that 'sociology is a martial art' and intensify it, by accepting that, in so many ways, martial arts studies is a martial art. The challenge is to understand both putative entities here ('martial arts' and 'martial arts studies') at the same time and in ways that are adequate to the complexity, forces, violences, vicissitudes, promises, possibilities, and potentials of their 'passion and activity' without any 'pre-emptive prohibition and limitation of activity', by reducing, simplifying, defining, or consigning either element to triviality.

This struggle, both challenging and fruitful, is evident in the entries that follow. Douglas Wile begins the conversation with a detailed investigation of four recent document finds related to the history and development of taijiquan. Far from setting anything to rest, Wile explores the ways in which these documents have reignited long simmering arguments about the origins of the art while forcing martial arts studies scholars in China to rethink not just their theories but also the relationship between historical research, questions of Chinese identity, and the limits of academic freedom. This article was originally conceived as a short review of Lars Bo Christensen's latest book, Tai Chi: The True History and Principles [2016]. Yet it soon became apparent that a far wider treatment of the subject was required to set the stage for any Western scholarly examination of the documents that have reanimated the academic debates within China on Taijiquan's origins. Only in this way can the significance and scope of these developments be appreciated.

From there, our attention shifts to the Brazilian art of capoeira. Lauren Miller Griffith begins her study by noting that instruction in capoeira is a highly embodied practice. Yet, the art generates an immense number of virtual tutorials on social media platforms such as YouTube. Turning her attention to the comments sections found beneath such videos, Griffith investigates the various ways in which these conversations both spread the specific training ethos of the art as well as function as an invitation to certain students to seek out the embodied training community. 
MARTIAL

ARTS STUDIES

In the following article, Gabriel Facal draws on his extensive background and anthropological fieldwork in an exploration of the fundamental factors that unite the diverse world of the Malay fighting systems. Moving away from the term 'martial art', he argues that to understand these combative practices within their own cultural context they are better viewed as a progressive series of 'martial initiation rituals'. He then explores the ways in which key political and social markers of 'Malayness' are consolidated through these practices.

Mario Staller, Benjamin Zaiser, and Swen Körner also focus on questions of pedagogy and training. Their study focuses on modes of instruction in combative practices seen in the Western world, including those employed within the realm of civilian self-defence. After critiquing concepts such as 'realism' and 'reality based training', they propose their own 'Trade-Off Model of Simulation Design' to help diverse types of instructors make better choices when designing testing or training regimes.

The last six months have been an exciting time as several important books and collections have been released. Three of these are discussed below. Sixt Wetzler begins by offering an assessment of Paul Bowman's latest work, Mythologies of Martial Arts [2017a]. Incidentally, this volume is the second to be released by Rowman \& Littlefield International's newly launched martial arts studies book series.

Lauren Miller Griffith's In Search of Legitimacy: How Outsiders Become Part of the Afro-Brazilian Capoeira Tradition [Griffith 2016] is then discussed by Kyle Green. This volume is based on her extensive ethnographic research in Brazil, and hence explores a different aspect of Griffith's research than the previously mentioned article. Finally, in keeping with the topic of South American martial arts, Benjamin Judkins reviews Michael J. Ryan's exploration of Venezuelan Stick Fighting [Ryan 2017]. In this ethnographic study Ryan addresses themes and topics relevant to a wide range of martial arts studies scholars interested in the ways that local fighting systems are subjected to modernizing and civilizing processes.

Taken together these articles and reviews offer a cross-section of some of the very best work being produced in martial arts studies today. Drawing on a wide variety of disciplinary skills, and addressing fighting practices in many areas around the globe, each of these authors makes a notable contribution to our understanding of both their subject and the disciplinary specific questions that surround it. Taken as a set they illustrate the progress that can be made when a deep exploration of the martial arts informs our evolving understanding of martial arts studies as a distinct field of study. It is the strength of such work, more than our own pondering of the problems of triviality, which establishes the substance of martial arts studies. 


\section{REFERENCES}

Bowman, Paul. 2008. Deconstructing Popular Culture. London: Palgrave Macmillan.

Bowman, Paul. 2010. Theorizing Bruce Lee: Film-Fantasy-Fighting-

Philosophy. Amsterdam: Rodopi.

Bowman, Paul. 2015. Martial Arts Studies: Disrupting Disciplinary Boundaries. London: Rowman and Littlefield.

Bowman, Paul. 2017a. Mythologies of Martial Arts. London: Rowman \& Littlefield.

Bowman, Paul. 2017b. 'The Definition of Martial Arts Studies', Martial Arts Studies 1, 6-23.

doi.org/10.18573/j.2017.10092

Christensen, Lars Bo. 2016. Tai Chi: The True History and Principles. Denmark: Self-Published.

Fabian, Johannes. 1983. Time and the Other: How Anthropology Makes Its Object. New York: Columbia University Press.

Farrer, Douglas S. and John Whalen-Bridge. 2011. 'Introduction: Martial Arts, Transnationalism, and Embodied Knowledge', in Martial Arts as Embodied Knowledge: Asian Traditions in a Transnational World, edited by Douglas S. Farrer and John Whalen-Bridge. Albany: SUNY Press, 1-28.

Griffith, Lauren Miller. 2016. In Search of Legitimacy: How Outsiders Become Part of the Afro-Brazilian Capoeira Tradition. New York City: Berghahn Books.

Hall, Stuart. 1992. 'Cultural Studies and Its Theoretical Legacies', in Cultural Studies, edited by Lawrence Grossberg, Cary Nelson, Paula Treichler. London: Routledge, 277-94.

Judkins, Benjamin N. and Jon Nielson. 2015. The Creation of Wing Chun: A Social History of the Southern Chinese Martial Arts. Albany, NY: SUNY Press.

Lorge, Peter. 2012. Chinese Martial Arts: From Antiquity to the Twenty First Century [Kindle Edition]. Cambridge: Cambridge University Press. www.amazon.co.uk.

Marchart, Oliver. 2007. Post-Foundational Political Thought: Political Difference in Nancy, Lefort, Badiou, and Laclau. Edinburgh: Edinburgh University Press.

Morris, Meaghan. 1988. 'Banality in Cultural Studies', Discourse 10.2 (Spring-Summer), 3-29.

Mowitt, John. 2003. 'Cultural Studies, in Theory', in Interrogating Cultural Studies: Theory, Politics, and Practice, edited by Paul Bowman. London: Pluto Press, 175-188. 
MARTIAL

ARTS STUDIES
Readings, Bill. 1996. The University in Ruins. Cambridge, M.A.: Harvard University Press.

Ryan, Michael J. 2016. Venezuelan Stick Fighting: The Civilizing Process in Martial Arts. New York: Lexington Books.

Singleton, Mark. 2010. Yoga Body: The Origins of Modern Posture Practice. Oxford: Oxford University Press.

Spivak, Gayatri Chakravorty and Sneja Gunew. 1993. 'Questions of Multiculturalism', in The Cultural Studies Reader, edited by Simon During. London: Routledge, 193-202.

Storey, John. 2000. Cultural Theory and Popular Culture: An Introduction. New York: Longman.

Wetzler, Sixt. 2015. 'Martial Arts Studies as Kulturwissenschaft: A Possible Theoretical Framework', Martial Arts Studies 1, 20-33. doi.org/10.18573/j.2016.10016

Wile, Douglas. 2014. 'Asian Martial Arts in the Asian Studies Curriculum', JOMEC Journal 5. Available at: https://publications. cardiffuniversitypress.org/index.php/JOMEC/article/view/334/340.

Young, Lola. 1999. 'Why Cultural Studies?', Parallax 5.2, 3-16. doi.org/10.1080/135346499249669

Young, Robert J. C. 1992. 'The Idea of a Chrestomathic University', in Logomachia: The Conflict of the Faculties, edited by Richard Rand. Lincoln: University of Nebraska Press.

Žižek, Slavoj. 2001. Did Somebody Say Totalitarianism?: Five Interventions in the (Mis) use of a Notion. London: Verso. 


\section{ABOUT THE JOURNAL}

Martial Arts Studies is an open access journal, which means that all content is available without charge to the user or his/her institution. You are allowed to read, download, copy, distribute, print, search, or link to the full texts of the articles in this journal without asking prior permission from either the publisher or the author.

The journal is licensed under a Creative Commons AttributionNonCommercial-NoDerivatives 4.0 International License.

\section{@creative commons (i) $\circledast \ominus$}

Original copyright remains with the contributing author and a citation should be made when the article is quoted, used or referred to in another work.

\section{CARDIFF \\ UNIVERSITY \\ PRIFYSGOL \\ Cardiff University Press \\ Gwasg Prifysgol Caerdydd}

CAERDYB

Martial Arts Studies is an imprint of Cardiff University Press, an innovative open-access publisher of academic research, where 'open-access' means free for both readers and writers. cardiffuniversitypress.org

Journal DOI

10.18573/ISSN.2057-5696

Issue DOI

$10.18573 / \mathrm{n} .2017 .10182$

Accepted for publication 30 June 2017

Martial Arts Studies

Journal design by Hugh Griffiths 


\section{MARTIALARTSSTUDIES.ORG \\ TWITTER.COM/MASTUDIES}

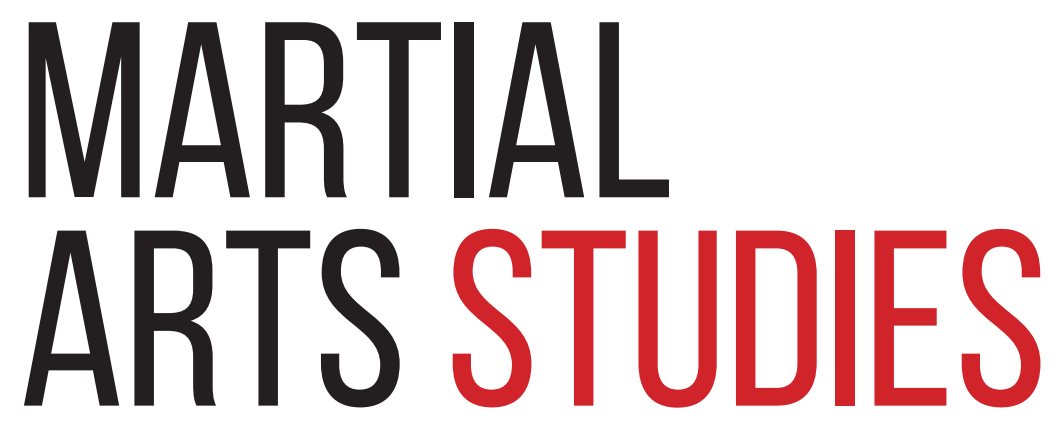

\section{EDITORS}

Paul Bowman

Benjamin N. Judkins

\section{EDITORIAL ASSISTANT}

\section{Kyle Barrowman}

To discuss publication or to submit a paper please contact:

martial.arts.studies@gmail.com

\section{EDITORIAL ADVISORY PANEL}

Oleg Benesch University of York

Stephen Chan SOAS

Greg Downey Macquarie University D.S. Farrer University of Guam

Adam Frank University of Central Arkansas Thomas A. Green Texas A\&M University

T. J. Hinrichs Cornell University Leon Hunt Brunel University London Felipe P. Jocano Jr University of the Philippines Gina Marchetti Hong Kong University Meaghan Morris The University of Sydney Daniel Mroz University of Ottawa Meir Shahar Tel Aviv University Dale Spencer Carleton University Douglas Wile Alverno College Phillip Zarrilli Exeter University, Emeritus 